\title{
Imagining nanotechnology: cultural support for technological innovation in Europe and the United States
}

\author{
George Gaskell, Toby Ten Eyck, Jonathan Jackson, \\ and Giuseppe Veltri
}

This paper compares public perceptions of technologies in the United States and Europe. Asked whether nanotechnology will improve our way of life, 50 percent of the US sample say "yes" and 35 percent say "don't know." The European figures are almost the mirror image, 29 percent saying "yes" and 53 percent saying “don't know." People in the US are also more optimistic than Europeans about eight more familiar technologies. We suggest that people in the US assimilate nanotechnology within a set of pro-technology cultural values. By contrast, in Europe there is more concern about the impact of technology on the environment, less commitment to economic progress and less confidence in regulation. These differences in values are reflected in media coverage, with more emphasis on the potential benefits of nanotechnology in the US than in the UK. Finally, we speculate on possible futures for the reception of nanotechnology in the US and Europe.

\section{Introduction}

Could we see a transatlantic divide in the public reception of nanotechnology, as has been seen for agricultural biotechnology? While many citizens of the United States are relaxed about genetically modified crops and foods, European public opinion has constrained their development and adoption (Gaskell et al., 1999, 2001; Ten Eyck et al., 2004). In this paper, we show that the US has a more supportive culture for the adoption and development of nanotechnology than Europe. Through an analysis of mass media reportage we also find a greater emphasis on potential benefits versus potential risks in the US compared to the UK. We conclude with some comments on possible futures for nanotechnology.

There are similarities between societal responses to nanotechnology and biotechnology. In 1974, at the dawn of biotechnology, the Berg letter in Science (Berg et al., 1974) on the potential biohazards of recombinant DNA molecules led to the Asilomar conference at which a self-imposed scientific moratorium on research was declared until the potential risks were clarified. In 2002, an attempt was made to persuade attending heads of state at the World Summit on Sustainable Development in Johannesburg to support another moratorium, this time on the development of nano-materials.

Biotechnology gave rise to both utopian and dystopian visions for society. Where the supporters of biotechnology saw vast opportunities for economic growth and better quality 
of life through the appliance of science, opponents saw biotechnology as "playing god" and opening up a Pandora's box with frightening and unknown consequences, brought alive by Michael Crichton's Jurassic Park. Nanotechnology is beginning to mobilize equally polarized visions of the future. With the ability to engineer and control systems at the nanometric scale, the enthusiasts predict transformative opportunities in areas as diverse as the environment, medical practice, electronics and novel materials. For the critics, the quality of life will be threatened by out-of-control self-replicating systems, miniaturized weapons of mass destruction, invisible surveillance techniques, and unknown impacts of nanotubes-scenarios depicted in Crichton's latest novel Prey.

Just as in the early days of biotechnology, nanotechnology is attracting considerable funds for research and development. Lux Research forecast government investment to rise to \$4.6 billion this year, with North American, Asian and European economies each accounting for around one-third of this amount (Lux Research, 2004). The race is on to be the world leader in a technology that has been predicted by the US National Science Foundation to be worth trillions of dollars in the next decade. And just as with biotechnology, there are calls for urgent attention to be given to the social, ethical, legal and environmental aspects of nanotechnology and for public dialogue to guide the sustainable development of this new science and technology (e.g. Brumfiel, 2003; Einsiedel and Goldenberg, 2004; Mehta, 2004; the Royal Society, 2004).

It was the future significance of public perceptions of nanotechnology that led us to include questions on the topic in a European Union (EU)/US survey on public perceptions of biotechnology in 2002/3.

\section{The surveys}

The Eurobarometer survey is a multi-stage, random probability face-to-face sample survey. In each EU country, a number of sampling points are drawn with probability proportional to population size and population density. Field work was conducted in September and October 2002. With samples of about 1000 interviews in each country, the total sample of about 15,000 respondents gives confidence limits of \pm 0.8 percent for a $50 / 50$ percent split. The US survey is a random probability telephone survey with field work conducted between December 2002 and February 2003. The sample of about 850 gives confidence limits of \pm 3.4 percent for a 50/50 percent split.

In Europe and the US, respondents were asked, "do you think nanotechnology will improve our way of life in the next 20 years, it will have no effect, or it will make things worse?"; a "don't know" response was included. This question set also included eight other more familiar technologies, such as the Internet, solar energy and mobile telephones.

Other questions in the survey of biotechnology are used in the present analysis, with cumulative scales constructed for each set. First, confidence in key actors and decision takers was measured by asking respondents: "Now I'm going to ask you about some people and groups involved in the various applications of modern biotechnology and genetic engineering. Do you suppose they are doing a good job for society or not doing a good job for society?" The targets comprised government, industry, university scientists and scientists in industry.

Second, environmental values were elicited using three attitude statements. These were: "Nature can withstand human actions"; "Modern technology has upset the balance of nature"; and "Exploiting nature is unavoidable if humankind is to progress."

Third, progress values were measured using three statements. These were: "Economic 
growth brings better quality of life"; "What is good for business is good for the citizens"; and "Private enterprise is the best way to solve [our country]'s problems."

And finally, interest in science was measured with the following statements: "I am interested in science and technology"; "I feel well informed about science and technology"; and "I understand science stories in the news" (for details of the Eurobarometer survey on biotechnology see Gaskell et al., 2003).

\section{Results}

Before presenting the results on transatlantic differences in optimism about nanotechnology, an explanation of what the answers may mean is necessary. Since few members of the public will be familiar with nanotechnology, the survey findings should not be treated as a vote or referendum. Rather, we believe that the question opens a window into public beliefs and values about science and technology, and particularly technological innovation. It does so because when asked whether nanotechnology will improve our way of life or not, some may admit their ignorance and opt for the "don't know" response. Others, however, will give it a meaning or representation by association with other more familiar things, for example with a particular technology such as biotechnology or with technology in general. Such associations may lead to other implications, often reflecting people's beliefs and values-technology equals progress and makes for a better life, or biotechnology has brought new risks and dangers to society. Hence the distribution of responses-optimistic and pessimistic-reveals something about the perceptions of technology and how such perceptions influence the reception of a new technology. Table 1 presents the findings.

Table 1 shows some striking similarities and differences between the publics in Europe (as a whole) and the US. First, consider the similarities. The percentages saying that nanotechnology will have "no effect" and those saying "it will make things worse" are more or less the same. With a mere 6 percent of Europeans taking a pessimistic view of nanotechnology, claims that "Old Europe" is culturally anti-technology must be treated with caution.

However, the differences are apparent in the percentages of people saying "it will improve our way of life" and "don't know." For the US, 50 percent are optimistic, with 35 percent saying "don't know." In Europe the situation is the mirror image: 53 percent say

Table 1. Optimism and pessimism: perceptions of nanotechnology in the United States and Europe

\begin{tabular}{|c|c|c|c|c|c|c|c|c|c|}
\hline & & Europe & & & & & & & \\
\hline & US & 16 & Ireland & Portugal & UK & Netherlands & Greece & Italy & Spain \\
\hline Don't know & 35 & 53 & 68 & 63 & 61 & 59 & 55 & 54 & 52 \\
\hline Will improve & 50 & 29 & 18 & 24 & 24 & 28 & 26 & 32 & 39 \\
\hline No effect & 12 & 12 & 6 & 6 & 10 & 9 & 5 & 8 & 7 \\
\hline \multirow{2}{*}{$\begin{array}{l}\text { Will make things } \\
\text { worse }\end{array}$} & 4 & 6 & 8 & 7 & 5 & 5 & 14 & 7 & 3 \\
\hline & France & Belgium & Germany & Sweden & Austria & Denmark & Finland & Norway & Luxembourg \\
\hline Don't know & 52 & 49 & 49 & 48 & 47 & 39 & 36 & 34 & 30 \\
\hline Will improve & 33 & 30 & 21 & 43 & 28 & 46 & 34 & 40 & 45 \\
\hline No effect & 10 & 14 & 22 & 7 & 17 & 10 & 26 & 12 & 15 \\
\hline $\begin{array}{l}\text { Will make things } \\
\text { worse }\end{array}$ & 5 & 7 & 7 & 2 & 9 & 6 & 4 & 15 & 10 \\
\hline
\end{tabular}


they "don't know" and 29 percent say they are optimistic. These figures mask considerable country variations, but for the UK, Germany and France, the major European trading partners of the US, the contrast is readily apparent. In passing, of the European countries approaching the level of optimism in the US (e.g. Denmark, Luxembourg and Sweden), are there also the more positive perceptions of agri-food biotechnologies that are found in the US? The answer is no-all these countries are on average opposed to agricultural biotechnologies (Gaskell et al., 2003).

Overall, while more Europeans are likely to suspend judgment about nanotechnology and opt for a "wait and see" position, people in the US are more likely to take an optimistic stance on this, as yet, unknown technology.

These differences on nanotechnology parallel differences in views about existing and more familiar technologies. In the question set concerning optimism and pessimism about nanotechnology, eight other technologies were included: computers and information technology, solar energy, space exploration, genetic engineering, telecommunications, the Internet, mobile telephones and nuclear power. An index of technological optimism was made by counting the number of technologies that people agreed would "improve our way of life in the next 20 years." For the purposes of the following analysis this index of technological optimism excluded nanotechnology. The mean for technological optimism in the US is 5.74 and for Europe 4.50, a difference that is statistically significant $(t=16.13$; $p<.005)$.

Figure 1 plots the number of technologies about which people are optimistic against the percentage of respondents who say they are optimistic about nanotechnology. Among the US public there is a steep rise in optimism about nanotechnology after only 1 on the scale of technological optimism. By 2 on the scale, 60 percent are optimistic about nanotechnology. By contrast Europeans need to be optimistic about seven other technologies before a similar level of optimism about nanotechnology is reached. This suggests a qualitative difference in the way in which new technologies are viewed in the US and Europe. It appears that people in the US greet innovation with enthusiasm, while Europeans are less likely to give it the benefit of the doubt, unless they are already optimistic about a number of other technologies.

This suggests that people in the US are much more likely to assimilate nanotechnology, within a positive framework. We speculate that for people in the US, technological innovation has positive connotations, for example, leading the world, economic development, employment prospects and better quality of life. These associations reflect collective experience and shared values and come together into what might be called a culture of support for technology and innovation.

To explore the beliefs and values lying behind the ways people make sense of nanotechnology, we compare, using logistic regression, the "optimists"- those agreeing that nanotechnology will improve our way of life, and those taking a "wait and see" position-saying "don't know" about the future contribution of nanotechnology. The model predicts the probability of being an "optimist" compared to a "wait and see" based on the following independent variables: gender, age, level of education, and separate indices of progress values, environmental values, interest in science and confidence in key actors and decision takers.

In Table 2, model 1 confirms that the probability of being an optimist is significantly greater in the US than in Europe-the odds of being an optimist are 61 percent less in Europe than in the US. Model 2 adds the independent variables, the demographics and the scores on the values and beliefs scales. In terms of demographics, the probability of being an optimist is higher for males, younger people, and those with more education. Such correlates 


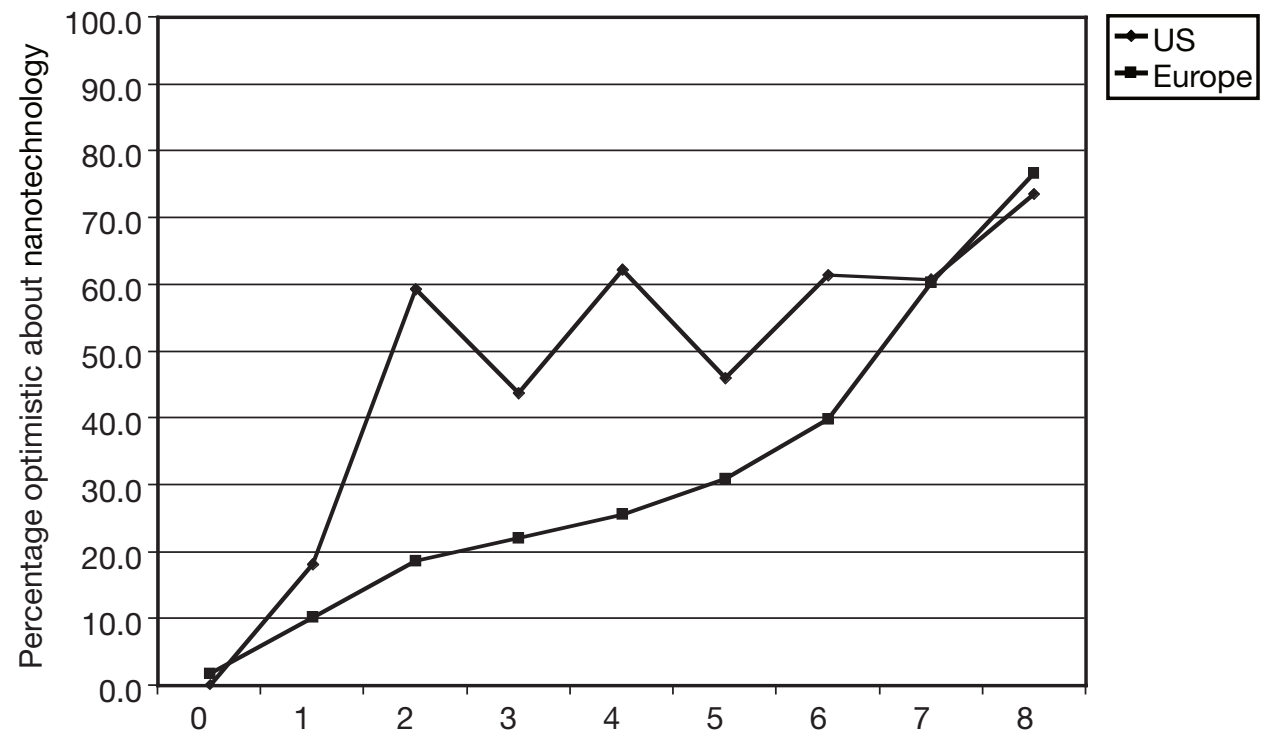

Number of existing technologies that respondents are optimistic about

Figure 1. Optimism about technology in general and nanotechnology in general.

Table 2. Parameter estimates of the logistic regressions

\begin{tabular}{|c|c|c|c|c|}
\hline Variables & $B$ & Std. error & $\operatorname{Exp}(B)$ & $p$ \\
\hline \multicolumn{5}{|l|}{ Model $1(n=14554)$} \\
\hline Constant & 0.44 & 0.08 & 0.00 & \\
\hline US_EU $(\mathrm{US}=0$, Europe $=1)$ & -0.93 & 0.08 & 0.39 & 0.00 \\
\hline \multicolumn{5}{|l|}{ Model $2(n=7651)$} \\
\hline Constant & -1.89 & 0.18 & 0.00 & \\
\hline US_Europe $(\mathrm{US}=0$, Europe $=1)$ & -0.22 & 0.10 & 0.80 & 0.03 \\
\hline Gender $(0=$ female, $1=$ male $)$ & 0.27 & 0.05 & 1.30 & 0.00 \\
\hline Age $15-24$ (reference category: age $65+$ ) & 0.47 & 0.10 & 1.61 & 0.00 \\
\hline Age $25-34$ & 0.34 & 0.08 & 1.41 & 0.00 \\
\hline Age $35-44$ & 0.44 & 0.08 & 1.56 & 0.00 \\
\hline Age $45-54$ & 0.33 & 0.09 & 1.39 & 0.00 \\
\hline Age $55-64$ & 0.14 & 0.09 & 1.17 & 0.11 \\
\hline Education 16-19 (reference category: low education) & 0.16 & 0.07 & 1.17 & 0.03 \\
\hline Education $20+$ & 0.50 & 0.07 & 1.64 & 0.00 \\
\hline Free-market liberal economic values & 0.05 & 0.03 & 1.06 & 0.05 \\
\hline Environmental values & -0.19 & 0.03 & 0.83 & 0.00 \\
\hline Interest in science & 0.26 & 0.01 & 1.29 & 0.00 \\
\hline Confidence & -0.04 & 0.02 & 0.96 & 0.05 \\
\hline
\end{tabular}

parallel research on risk perception (e.g. Savage, 1993) but are not of concern to our current question - the role of beliefs and values.

In the context of this question, the findings point to an interesting syndrome of characteristics related to the "optimistic" and "wait and see" positions on nanotechnology, 
and, by implication, to new technologies in general. Controlling for region (US or Europe) and the demographic characteristics of respondents, we find that the optimists have a greater interest in science, a more positive view of progress and of the robustness of nature, and more confidence in key actors and decision takers creating, exploiting and regulating biotechnology. Separate analyses show that, apart from confidence where there is no difference, these beliefs and values are more widely held in the US than in Europe $(p<.001)$.

Those taking the "wait and see" approach to nanotechnology are less interested in and less persuaded of the benefits of progress. They see nature as under threat from science and have less confidence in industry, scientists and government. These beliefs are more prevalent in Europe than in the US and echo metaphysical values that, in both traditional and more modern forms, have challenged the "science as progress" basis of the utilitarian ethic. Interestingly, similar differences in value orientations have been found for the supporters and opponents of agri-food biotechnologies (Gaskell et al., 2004).

Overall, these results provide support for the hypothesis that values lie behind people's views on technological innovation. Taking statistical account of the highly significant effects of region and demographics, values still enter in the equation of public perceptions of new technology.

What of the future? Doubtless the mass media will play a role in the shaping of public attitudes to nanotechnology. And there are early indications of a divergence in the amount and tone of coverage across the Atlantic. We report on two opinion leading newspapersthe New York Times and the London Independent. We also analyzed other newspapers, but the Washington Post had relatively few articles, the London Guardian adopted a rather negative position and the coverage of the London Times was comparable to that of the Independent. So, given their generally similar liberal orientation, we base our analysis of the coverage of nanotechnology on the New York Times and the Independent.

Using Lexis-Nexus with the search words "nano," "nanotechnology" and "nanotechnologies" all the articles from 1990 to 2003 were collected. A small number of articles that merely included the word nanotechnology (or a synonym) but without any further substantive content were excluded.

The amount of media coverage of nanotechnology is relatively low, as seen in Figure 2. Overall there are a mere 110 articles in the New York Times and 66 in the Independent from 1990 to 2003. While there is an upward trend from 1999, it appears that nanotechnology is only just appearing on the radar screen of press and public attention.

The articles were content analysed with the Nvivo 2 software to identify the prevalence of themes of benefit-descriptions or examples of advances and improvements of any kind resulting from nanotechnology, and risks-a description of possible threats or dangers consequent upon research and/or the adoption of nanotechnology. Articles that made no reference to risks or benefits were excluded from the following analysis. Figure 3 shows that in both the US and the UK, 2003 saw an increase in the discussion of both risks and benefits compared to 2002, but there was considerably more reference to benefits in the New York Times compared to the Independent. Interestingly, three sources dominate the increasing risk coverage from 2002 to 2003: Michael Crichton's 2002 novel Prey; the ETC Group (2003) report; and a speech by HRH Prince Charles in 2003.

While the media coverage is more slanted towards a supportive culture of science and technology in the US, given the low level of coverage it seems unlikely that the media have yet to have much impact on public opinion. But if what we see over the past four years turns into a trend-more emphasis on risk in Europe than in the US- then this is likely to have implications for public support for nanotechnology. 


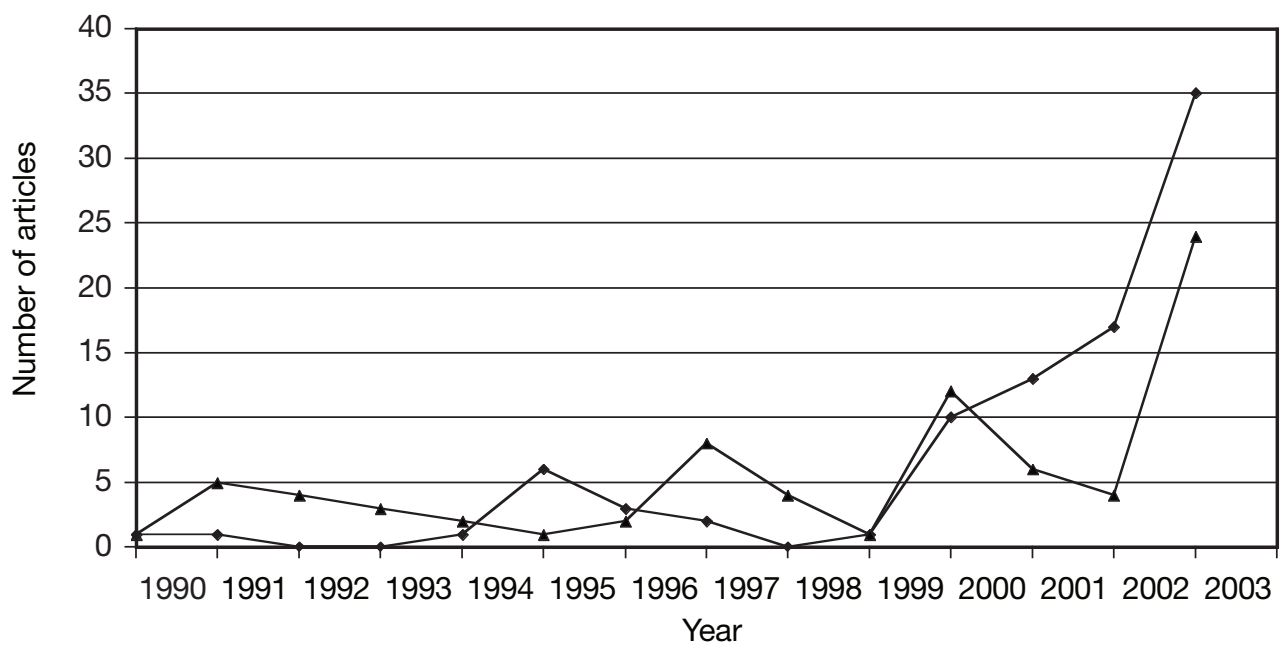

New York Times

Independent

Figure 2. Number of articles per year featuring nanotechnology.

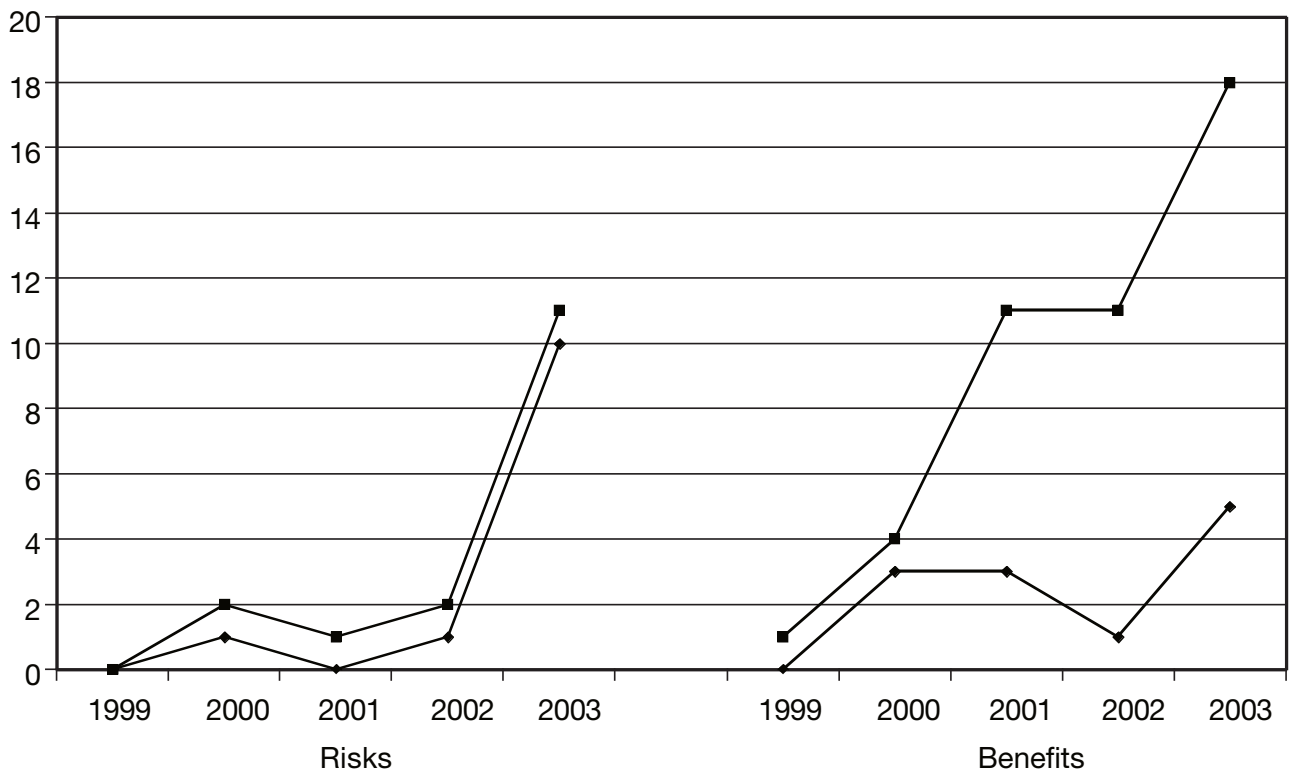

Independent $\rightarrow$ New York Times

Figure 3. Benefits and risks of nanotechnology in media reportage. 


\section{Discussion}

So what might happen in the coming years? Is nanotechnology set to experience the same troubles and controversies that have accompanied biotechnology, particularly in Europe?

In the US, if the widespread optimism is sustained, it is likely to keep nanotechnology out of public controversy. There is little incentive to discuss what everyone is agreed on. In Europe, however, there is less unquestioning enthusiasm for this technology and less reporting of potential benefits in the UK than in the US. Is this a context in which nanotechnology could become politicized, as has happened for biotechnology (see for example Bauer and Gaskell, 2002)? If a heated public debate takes place in Europe, could it affect opinion in the US?

A key issue for the public debate will be the framing of this new technology in media and other arenas. Will nanotechnology come to be seen as a radical departure, a paradigm shift in science and technology, or as merely an extension of existing practice, only a lot smaller? In the public mind, will it be seen as an extension of biotechnology and, if so, as another beneficial application like biomedicine, or as one that is associated with risks and dangers? Without doubt, the mass media, both a product and producer of popular culture, will have an important impact in this respect.

And how will governments react? Will they find themselves in a conflict of interests as they strive to promote nanotechnology and at the same time exercise regulatory control? Will "substantial equivalence" be assumed and existing regulations deemed sufficient, or, as with biotechnology in Europe, will a process-based regulatory system be required, leading to the creation of new regulatory bodies and "nano laws"? In Europe, will the European Commission lead, avoiding the problems of harmonizing multi-level policymaking, or will some of the governments of the EU member states find themselves pressed into legislation to calm public anxieties?

Yet, the relatively strong association between public perceptions of nanotechnology and other technologies suggests that the debates over nanotechnology will, in reality, have a wider agenda. And that agenda centers around the issue of science, technology and society. It is not about the esoterics of nanotechnology but rather the type of society that new developments in this science and technology make possible.

The conflicts that will emerge are about fundamental questions: "what sort of society do we want and how can new technology help in achieving it?" These are questions about ethics and social values; science alone cannot answer them. And if socially sustainable technological innovation is a societal goal, appropriate platforms for such debates will need to be established if we are to avoid reliving the type of conflicts that raged over biotechnology in the mid to late 1990s.

\section{Acknowledgements}

This research was supported by grants from the EC Directorate General for Research for the project "Life Sciences in European Society" (QLG7-CT-1999-00286) and the US National Science Foundation, Ethics and Values Studies (0115380). We are grateful for the constructive comments of two anonymous reviewers.

\section{References}

Bauer, M.W. and Gaskell, G. (eds) (2002) Biotechnology: The Making of a Global Controversy. Cambridge: Cambridge University Press.

Berg, P., Baltimore, D., Boyer, H.W., Cohen, S.N., Davis, R.W., Hogness, D.S., Nathans, D., Roblin, R., Watson, 
J.D., Weissman, S. and Zinder, N.D. (1974) "Potential Bio-hazards of Recombinant DNA Molecules," Science 185: 303.

Brumfiel, G. (2003) “A Little Knowledge," Nature 424: 246-8.

Einsiedel, E.F. and Goldenberg, L. (2004) "Dwarfing the Social? Nanotechnology Lessons from the Biotechnology Front," Bulletin of Science, Technology and Society 24: 28-33.

ETC Group (2003) From Genomes to Atoms: The Big Down. Winnipeg, Manitoba: ETC Group. Available: http:// www.etcgroup.org

Gaskell, G., Allum, N. and Stares, S. (2003) Europeans and Biotechnology in 2002. Available: http://europa.eu.int/ comm/public_opinion/archives/eb/ebs_177_en.pdf

Gaskell, G., Allum, N., Wagner, W., Kronberger, N., Torgersen, H. and Bardes, J. (2004) "GM Foods and the Misperception of Risk Perception," Risk Analysis 24(1): 183-92.

Gaskell, G., Bauer, M., Durant, J. and Allum, N. (1999) "Worlds Apart: The Receptions of GM Foods in Europe and the United States," Science 264(5426): 384-7.

Gaskell, G., Einsiedel, E.F., Priest, S., Ten Eyck, T., Allum, N. and Torgersen, H. (2001) "Troubled Waters: The Transatlantic Divide on Biotechnology Policy," in G. Gaskell and M.W. Bauer (eds) Biotechnology 1996-2000: The Years of Controversy, pp. 96-115. London: Science Museum Press.

Lux Research (2004) The Nanotech Report 2004. Available: http://www.luxresearchinc.com/tnr2004

Mehta, M.D. (2004) "From Biotechnology to Nanotechnology: What Can we Learn from Earlier Technologies?," Bulletin of Science, Technology and Society 24: 34-9.

Royal Society (2004) Nanoscience and Nanotechnologies: Opportunities and Uncertainties. London: The Royal Society.

Savage, I. (1993) "Demographic Influences in Risk Perception,” Risk Analysis 13: 413-20.

Ten Eyck, T., Gaskell, G. and Jackson, J. (2004) "Seeds, Food and Trade Wars: Public Opinion and Policy Responses in the US and Europe," Journal of Commercial Biotechnology 10(3): 258-67.

\section{Authors}

George Gaskell is professor of social psychology and director of the Methodology Institute at the London School of Economics. His research interests include risk, risk perception, trust and social, ethical and legal aspects of technological innovation. He is a member of the Science in Society committee of the Royal Society and of the Advisory Panel on Science and Society for the 6th Framework Programme of the European Commission.

Toby Ten Eyck is an assistant professor in the Sociology Department and National Food Safety and Toxicology Center at Michigan State University. His research focuses on media presentations of food safety related issues and how audiences interpret that information. His work has been published in journals including Rural Sociology, Science Communication and the International Journal of Food Science and Technology. 
Jonathan Jackson is a lecturer in research methods in the Methodology Institute at the London School of Economics. Previously he was an Economic and Social Research Council (ESRC) postdoctoral fellow and a visiting scholar at the Department of Psychology at New York University. In addition to interests in technology and society his research centers on public perceptions of crime, community and policing.

Giuseppe Veltri is a Ph.D. student in the Department of Social Psychology at the London School of Economics. His thesis concerns the socio-genesis of beliefs in different groups in society, the process of sense making. The substantive area of investigation is nanotechnology, which offers a unique opportunity to research the process of "making sense" on a new scientific issue, itself in the making. The research is based on the assumption that the development and diffusion of a given technology is a social process in which public opinion may act as both a facilitator and a constraint.

Corresponding author: George Gaskell, Methodology Institute, London School of Economics, London WC2A 2AE, UK, e-mail: g.gaskell@1se.ac.uk 